\title{
A new tooth brushing approach supported by an innovative hybrid toothbrush- compared reduction of dental plaque after a single use versus an oscillating-rotating powered toothbrush
}

\author{
D. Klonowicz', M. Czerwinska', A. Sirvent ${ }^{2}$ and J-Ph. Gatignol ${ }^{3^{*}}$
}

\begin{abstract}
Background: An innovative hybrid toothbrush was designed functioning either in manual mode, in powered mode (sonic) or in combined mode (manual and powered). The primary aim of this study was to evaluate and compare the clinical efficacy of this first hybrid toothbrush (Elgydium Clinic/Inava Hybrid) used in combined mode to a marketed oscillating-rotating powered toothbrush (Oral-B Vitality) in the reduction of dental plaque after a single use. The secondary aims were to evaluate the tolerance and acceptability of each device.

Methods: It was a randomized, examiner-blind, single-center study performed on two parallel groups: hybrid toothbrush $(n=33)$ versus oscillating-rotating toothbrush $(n=33)$. A brushing exercise was conducted for two minutes on subjects presenting a "Silness and Löe Plaque Index" (PI) between 1.0 and 2.0 and a "Modified Gingival Index" between 1.0 and 2.0. They were not to have ever used an electric toothbrush. To assess the device effect after brushing, a paired t-test was applied on the change outcome (After-Before brushing). An unpaired t-test was used to compare the efficacy of both devices. A global tolerance assessment of each powered toothbrush was done on all the subjects. The number and percentage of reactions related to each toothbrush was collected and the final tolerance assessment was estimated.

Results: After a single use, the hybrid toothbrush used in combined mode presented a global anti-plaque efficacy characterized by a significant decrease of the global PI of $45 \%$ on average $(p<0.0001$; paired t-test). It was as effective as the oscillating rotating toothbrush in plaque removal ( $p>0.05$; unpaired t-test). The global tolerance of both toothbrushes was judged as "Good" and they were equally appreciated by the users.

Conclusion: The results of this one-time use trial demonstrate the efficacy of the hybrid toothbrush used in combined mode for plaque removal. The hybrid toothbrush design allows each user to adapt tooth brushing to his preference (manual / sonic / combined), his skills or his mouth condition. We hypothesize that such an individualized approach can favor long term compliance with oral health recommendations and improve global oral wellness.
\end{abstract}

Trial Registration: ISRCTN12394494, 20/02/2018 - Retrospectively registered.

Keywords: Powered toothbrush, Sonic toothbrush, Oscillating-rotating toothbrush, Dental plaque, Manual toothbrush, Hybrid toothbrush

\footnotetext{
* Correspondence: jean.philippe.gatignol@pierre-fabre.com

${ }^{3}$ Innovation Unit Consumer HealthCare, 17 avenue Jean Moulin, 81106

Castres Cedex, France

Full list of author information is available at the end of the article
}

(c) The Author(s). 2018 Open Access This article is distributed under the terms of the Creative Commons Attribution 4.0 International License (http://creativecommons.org/licenses/by/4.0/) which permits unrestricted use, distribution, and reproduction in any medium, provided you give appropriate credit to the original author(s) and the source, provide a link to the Creative Commons license, and indicate if changes were made. The Creative Commons Public Domain Dedication waiver (http://creativecommons.org/publicdomain/zero/1.0/) applies to the data made available in this article, unless otherwise stated. 


\section{Background}

Oral health is one of the major concerns of dental health care professionals [1]. Most of periodontal diseases (halitosis, gingivitis, periodontitis, gum abscesses, peri-implant mucositis, etc.) are bacteria-dependent, through biofilm formation and dental plaque accumulation [2]. Promotion of regular oral hygiene can contribute to the maintenance of a functional dentition throughout life [3]. Current available approaches to control bacterial plaque development can be categorized as either mechanical (toothbrushes, floss, interdental brushes, chewing sugar-free gums) or chemotherapeutical (toothpastes, mouthwashes, gels) [4]. In Western industrialized countries, the toothbrush is widely accepted as a simple, affordable and effective device to remove plaque in a shorter time $[5,6]$. To date, dental professionals recommend brushing teeth twice a day for two minutes $[7,8]$. However, a wide diversity in brushing methods does exist depending on the position and motion of the brush. There appears to be no consensus on the ideal technique neither for the general population nor for people of different ages or with particular dental conditions [9]. No method is satisfactory when considering interdental cleanliness. Tooth brushing is able to clean the buccal, lingual and occlusal tooth surfaces but the proximal and interdental areas are often stayed untouched [10] or roughly cleaned [11]. Furthermore, tooth brushing efficacy for plaque removal relies on several parameters: motivation and skills of the subject, the use of a brush that fits the mouth allowing it to reach all areas, as well as proper oral hygiene education with instructions on movement, duration and frequency of brushing [12]. As an example, the two-minute recommendation for brushing time is hardly ever reached in behavioral studies. Most people spend between 30 and $60 \mathrm{~s}$ brushing their teeth $[13,14]$, while plaque removal efficacy is known to be time-dependent [15-17].

Powered toothbrush was conceived in the 1950s with a view to improve and facilitate oral hygiene. It was designed to target patients with limited motor skills as well as orthodontic patients, who have difficulties in keeping their teeth hygienic and healthy [18]. Geriatric patients with impaired manual skills can also benefit from powered toothbrushes [19]. Since the 1980s, powered toothbrushes have rapidly developed to become an established alternative to manual tooth brushing $[20,21]$. Tremendous work has been done in order to improved toothbrush design, head and bristles. Several modes of action can be found on the market (oscillation-rotation, side-to-side sonic action, counter oscillation, circular, ultrasonic, ionic) but two technologies are dominating: oscillation-rotation and sonic. With the former, a small round brush head rotates in one direction and then the other, with the latter, a traditional brush head moves laterally form side to side with a high vibrational speed (mean frequency range $250 \mathrm{~Hz}$, i.e.
30,000 brush-strokes-per-minute). This latter agitates the fluids present in the mouth (water, saliva) to the degree that they are able to disrupt dental plaque colonies even beyond where the bristles of the brush actually touch [2224]. This fluid-dynamics cleaning action, although considered as a secondary cleaning effect, is characteristic of sonic toothbrushes.

A new generation of toothbrush called hybrid toothbrush has been recently developed. Hybrid toothbrush means that it can be used either in manual mode (motor off), in powered mode (sonic) or in combined mode (manual gesture associated to sonic vibrations). These various modes allow the user to adapt tooth brushing to his desire or his mouth condition. However, the use of combined mode corresponds to a new way of brushing. Indeed, usual recommendations for sonic tooth brushing imply minimal hand movements. In this case, hybrid toothbrush could be used by applying slight pressure by slowly moving the brush head with a light circular motion.

The primary aim of this study was to evaluate and compare the clinical efficacy of the first hybrid toothbrush (Elgydium Clinic/Inava Hybrid) using combined mode to a marketed oscillating-rotating powered toothbrush (Oral-B Vitality) in the reduction of dental plaque after a single use. The secondary aims of the study were to evaluate the tolerance and acceptability of each device.

\section{Methods \\ Experiment}

The experiment was a randomized, examiner-blind, single-center study performed on parallel group. It took place at Dermscan Poland (Gdansk, Poland). In Poland, an electric toothbrush is considered to be a domestic electric apparatus. Conducting a clinical study with such devices does not require any approval by an ethics committee. However, the study was conducted in compliance with Good Clinical Practices and in accordance with the "Declaration of Helsinki." Written informed consents for participation in the clinical study were obtained for all participants.

\section{Subjects}

The planned number of subjects to be analyzed was 30 minimum per group. In order to participate in the study, subjects had to be aged between 18 to 70 years old, to present at least 20 natural teeth, without implants, prosthesis or dental braces on the studied teeth. To qualify for the study, subjects had to present a "Silness and Löe Plaque Index" between 1.0 and 2.0 and a "Modified Gingival Index" between 1.0 and 2.0. They were not to have ever used an electric toothbrush. Subjects having undergone surgery, chemical or physical treatment in the mouth in the last 3 months as well as subjects using preventive dental medications, antibiotics and/or steroids for 1 week before the study were excluded. Written informed consents for 
participation in the clinical study of its result were obtained for all participants before the beginning of the study.

\section{Tested toothbrushes}

$>$ Hybrid toothbrush (Elgydium Clinic/Inava HybridPierre Fabre Oral Care): this toothbrush looks like a manual toothbrush with a traditional oval brush head shape associated to sonic technology (Fig. 1). It weights around 1.59 oz. The toothbrush neck is thin and flexible. The bristles have a conical design (18/100 at the basis and 1/ 100 at the tip) which increase softness. They are made of Tinex ${ }^{\oplus}$ fibers with rounded ends, offering high flexibility for a non-traumatic brushing of gums and enamel. The brushing technology can be chosen among three modes: manual, sonic or combined (manual and sonic). The sonic mode uses vibration technology; the brush head makes side-by-side movements and produces up to 28,000 strokes per minute for an effective plaque removal.

The instructions for use given to the subjects were the following (combined mode):

1. Wet the toothbrush (brush bristles) and apply a small amount of toothpaste.

2. Place the brush bristles in contact with the tooth with a $45^{\circ}$ inclination to the gums.

3. Turn the toothbrush on once in the mouth to activate the sonic mode.

4. Apply slight pressure by slowly moving the brush head with a light circular motion.

5. Keep an inclination (45 ) and constant contact with the teeth during brushing.

6. Be sure to clean all surfaces of your teeth; do not forget your tongue.

7. Brushing time: two minutes.

$>$ Oscillating-rotating toothbrush (Oral-B Vitality 2D Sensitive Clean - Procter \& Gamble): this rechargeable electric toothbrush possesses a small circular brush head, with soft and highly flexible bristles convenient for sensitive gums (Fig. 2). It weights approximately $5.29 \mathrm{oz}$. This toothbrush uses rotation-oscillation action (=rotary technology); the brush head spins in a motion and makes 16 degree movements. It performs 7600 oscillations per minute. The instructions for use given to the subjects were the following:

1. Wet brush head and apply a small amount of toothpaste. To avoid splashing, guide the brush head to your teeth before switching on the appliance.

2. Guide the brush head slowly from tooth to tooth, spending a few seconds on each tooth surface. Brush the gums as well as the teeth, first the outside, then the inside, finally the chewing surfaces. Do not press too hard or scrub. Do not forget to brush your tongue.

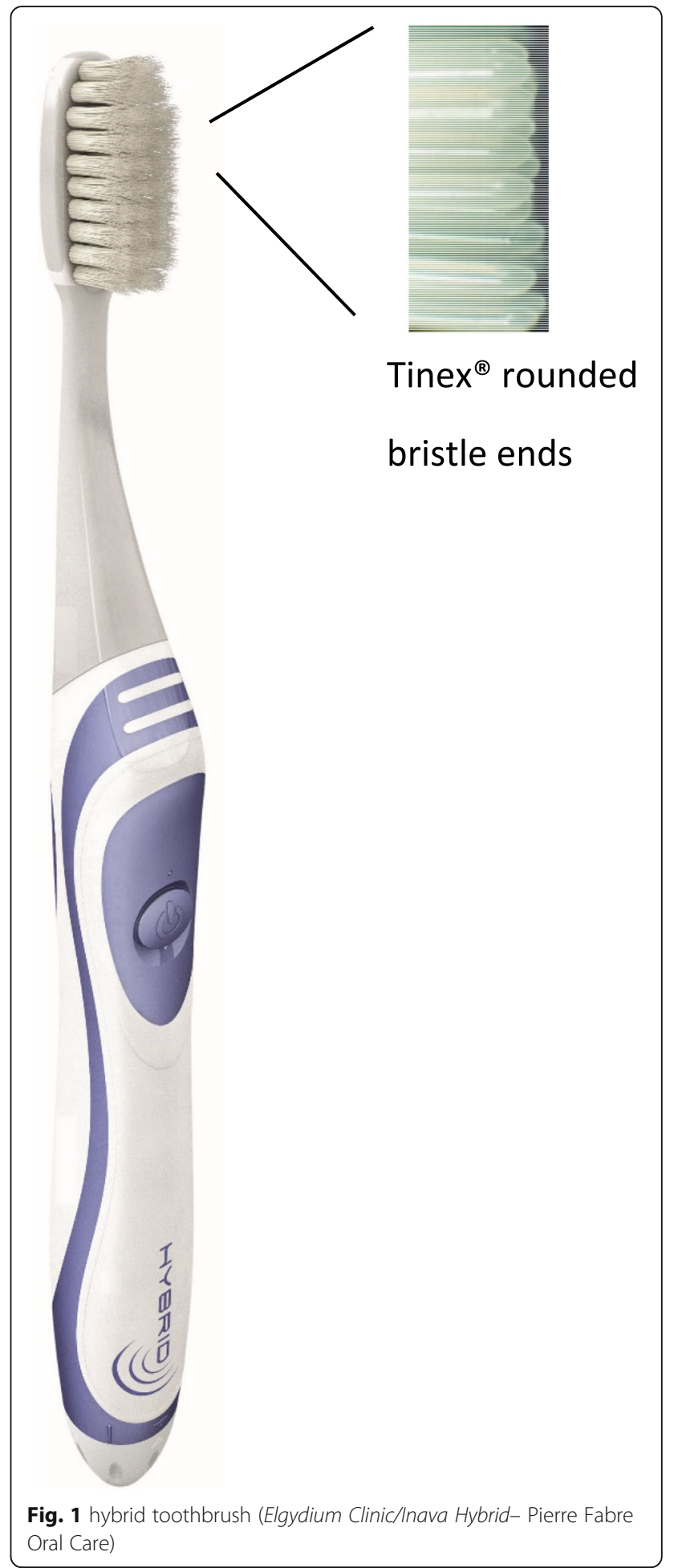

3. Brushing time: two minutes.

Trial schedule

On the day of the study, the subjects came to the laboratory after refraining from all oral hygiene procedures for $24 \mathrm{~h}$ and without eating, drinking and smoking for the 


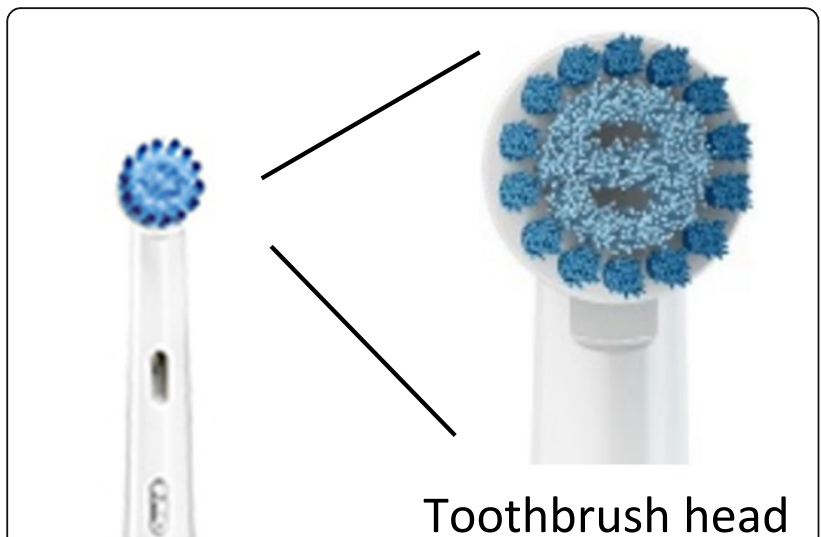

Toothbrush head

included in the study. After randomization, each participant received instructions on how to use the assigned toothbrush device. The same toothpaste was provided to all the subjects. A single brushing with the studied product (hybrid toothbrush) or the comparative product (oscillating-rotating device) was performed for exactly 2 minutes under supervision to ensure compliance with the manufacturer's usage instructions. Immediately after brushing, another clinical examination of the state of the oral cavity was performed by the dentist and another PI scoring was done. Possible adverse reactions were noted. For this post-brushing evaluation, the dentist was blinded as to the device used. The participants completed a self-assessment questionnaire of the products' acceptability after the first use.

\section{Evaluation tools}

> "Silness and Löe Plaque Index" (PI) [25]: this assessment is based on recording, on all natural teeth, the thickness of the plaque at the gingival margin rather than its coronal extent on the tooth surface area. The scoring system goes from 0 to 3 (0_no plaque / 1_deposit of invisible plaque but can be removed by a curette / 2_deposit of plaque covering $1 / 3$ of the cervical / 3_deposit of plaque in abundance (more than $1 / 3$ of the cervical)]. The index for the subject was obtained by summing the indexes for all surfaces (lingual and labial) of natural teeth and dividing by the number of surfaces examined. Variations (before brushing - after brushing) were calculated and statistics were performed to determine the significance of any variation. The device was considered effective if it induced a significant decrease in the score of the plaque.

> "Modified Gingival Index" (MGI) devised by Lobene et al. [26]: gum status was evaluated using a score ranging between 0 to 4 (0_absence of inflammation/ 1_mild inflammation or with slight changes in color and texture but not in all portions of gingival marginal or papillary / 2_mild inflammation, such as the preceding criteria, in all portions of gingival marginal or papillary / 3_moderate, bright surface inflammation, erythema, oedema and/or hypertrophy of gingival marginal or papillary / 4_severe inflammation: erythema, oedema and/or marginal gingival hypertrophy of the unit or spontaneous bleeding, papillary, congestion or ulceration). The MGI was scored for selected teeth $(12,16,24,36,32$ and 44). The scores of the four areas (buccal/lingual/mesial/distal) of the tooth were summed and divided by four to give the MGI for the tooth. For each subject, the MGI was obtained by adding the values of each tooth and dividing by the number of teeth assessed.

$>$ Tolerance assessment: before and after the first brushing, an examination of the subject's oral cavity was performed by the dentist to assess, either on soft tissues 
(gums, tongue, lips, palate) or hard tissues (teeth), the following signs:

- clinical signs: ulceration, desquamation, dyschromia, erythema, bleeding, papules, edema, cheilitis or other on soft tissues; dyschromia, tooth decay or other on hard tissues.

- functional signs: pruritus, stinging, pain, burning sensation, change in the quantity of saliva, oral dysesthesia, taste perversion, sensation of discomfort or other on soft tissues; dyschromia or other on hard tissues.

For each sign, the intensity was scored as: 0_none / 1_very mild / 2_mild/ 3_moderate.

A global tolerance assessment of each powered toothbrush was done on all the subjects who used the device at least once. The number and percentage of reactions related to each toothbrush was collected and the final tolerance assessment was estimated either as: Excellent (no functional nor physical signs related to the study) product observed or reported by the subjects) / Very good / Good / Moderate / Bad.

\section{Statistics}

The raw variations $(\Delta)$ of the different studied parameters were calculated according to the following formulas:

$$
\Delta=\left(\mathrm{PI}_{\mathrm{t} 1}-\mathrm{PI}_{\mathrm{t} 0}\right)
$$

with: PI: Silness and Löe Plaque Index; t0: before brushing; $\mathrm{t} 1$ : after brushing.

The descriptive statistics for quantitative data were computed for each time point, for each surface (lingual and labial) as well as for the change between (t1-t0).

To assess the effectiveness of the device after brushing, a paired t-test was applied on the change outcome (t1-t0). The normality assumption was checked with a Shapiro-Wilk test $(\alpha=0.01)$. The type I error probability $(\alpha)$ was set at $5 \%$ in bilateral mode. The software used was Microsoft Excel ${ }^{\circ} 2010$ and SAS ${ }^{\circ}$ v9.2.

\section{Results}

A total of 66 subjects participated in the study (33 per group). The baseline demographics of the randomized subjects are given in Table 1.

\section{Evaluation of plaque removal efficacy}

Mean values of PI scores before and after a single brushing with either powered toothbrush are presented in Table 2.

Under these study conditions, after a single use, the hybrid toothbrush presented a global anti-plaque efficacy characterized by a significant decrease of the global PI of $45 \%$ on average $(p<0,0001$; paired t-test); this effect was observed in $100 \%$ of subjects. The oscillating-rotating toothbrush used under the same conditions showed a similar efficacy: reduction of global PI of $43 \%$ on average $(p<0.0001$; paired t-test); effect observed in $100 \%$ of subjects.

For each tooth brushing technique, removal of plaque was more effective on the labial side than on the lingual side (mean reduction of PI of 53\% versus 37\% respectively for the hybrid toothbrush and 52\% versus $34 \%$ for the oscillating-rotating device). However, whatever the side and the device, the decrease of plaque index was statistically significant and observed on the totality of the participants.

The comparison of methods showed that the hybrid toothbrush (manual and sonic combination) was as effective as the oscillating rotating one in plaque removal after a single use $(p>0.05$; unpaired t-test).

\section{Global tolerance assessment}

$>$ With the hybrid toothbrush, 15 subjects (45\%) presented reactions with causality assessment "likely or very likely." The most common reaction was bleeding (12 subjects, with very mild or mild intensity).

$>$ With the oscillating-rotating powered toothbrush, 14 (42\%) subjects presented reactions with causality assessment "likely or very likely." For 13 out of 14 participants, the reaction was bleeding with very mild or mild intensity.

However, no subject was withdrawn of the study due to theses reactions. Subjects neither modified methods of brushing nor temporally stopped the brushing due to the reactions.

Table 1 Baseline demographics of randomized subjects

\begin{tabular}{llll}
\hline & & Hybrid $(n=33$ subjects $)$ & Oscillating-rotating $(n=33$ subjects $)$ \\
\hline Age (years) & Mean $( \pm$ SEM) & $27.5( \pm 5.6)$ & $30.2( \pm 7.4)$ \\
& Range & $18-42$ & $19-55$ \\
Gender & Male & 14 & 6 \\
& Female & 19 & 27 \\
LSPI & Mean $( \pm$ SEM) & $1.2( \pm 0.0)$ & $1.2( \pm 0.0)$ \\
MGI & Mean $( \pm$ SEM) & $1.3( \pm 0.0)$ & $1.2( \pm 0.0)$ \\
\hline
\end{tabular}


Table 2 evolution of mean PI after a single brushing for the hybrid and oscillating-rotating powered toothbrushes; comparison of devices' efficacy

\begin{tabular}{llllll}
\hline PI & Device & Variation $\Delta(\mathrm{t} 1$-t0) $($ mean \pm SEM) & $\Delta \%$ & Significance (paired t-test) & \% of subjects with a positive effect \\
\hline Global score & Hybrid & $-0.5 \pm 0.0$ & $-45 \%$ & $p<0.0001$ & $100 \%$ \\
& Oscillating-rotating & $-0.5 \pm 0.0$ & $-43 \%$ & $p<0.0001$ & $100 \%$ \\
& Comparison & $0.0 \pm 0.2$ & & $p=0.5474$ & (unpaired t-test) \\
Labial side & Hybrid & $-0.6 \pm 0.0$ & $-53 \%$ & $p<0.0001$ & $100 \%$ \\
& Oscillating-rotating & $-0.6 \pm 0.0$ & $-52 \%$ & $p<0.0001$ & $100 \%$ \\
& Comparison & $0.0 \pm 0.2$ & $-37 \%$ & $p<0.0001$ & (unpaired t-test) \\
Lingual side & Hybrid & $-0.5 \pm 0.0$ & $-34 \%$ & $p<0.0001$ & $100 \%$ \\
& Oscillating-rotating & $-0.4 \pm 0.0$ & & $p=0.3022$ & (unpaired t-test) \\
& Comparison & $-0.05 \pm 0.2$ & & &
\end{tabular}

According to the investigator, bleeding reactions could be due not only to the toothbrushes (bristles), but also to the fact that the participants used this type of toothbrush (powered) for the very first time. As the teeth brushing was done under supervision, the subjects could have brushed too intensively... Considering this, the dentist judged the global tolerance of both powered toothbrushes as "Good."

\section{Global appreciation of the powered toothbrushes}

The participants completed a subjective evaluation questionnaire after their first use. A summary of the answers is presented in Figs. 3 and 4.

$>$ The hybrid toothbrush was appreciated by the majority of the subjects for its characteristics; its intensity of vibration was just about right for $91 \%$ of the participants. The new hybrid sonic toothbrush was judged better than the usual manual one for $87 \%$ of the subjects.

$>$ The oscillating-rotating toothbrush was also liked by the majority of the subjects; its intensity of vibration was considered just about right for $94 \%$ of the participants.
$90 \%$ of the subjects rated the marketed oscillating-rotating toothbrush better than their usual manual one.

\section{Discussion}

The maintenance of periodontal health requires supragingival dental plaque removal. Tooth brushing is a key element in mechanical plaque control [6]. Several randomized, controlled clinical trials recognized a superiority of powered over manual toothbrushes in removing dental plaque $[19,20]$. Without distinction on the type of powered toothbrushes used, an overall benefit of $11 \%$ reduction in plaque was shown at one to 3 months and $21 \%$ at longer than 3 months [19]. With regards to gingivitis, a $6 \%$ reduction was shown at one to 3 months and an $11 \%$ over the long term. In 2010, different power toothbrush technologies were compared for plaque and gingivitis control [27]. The authors concluded that, over a period of four to 12 weeks, brushes with a rotating-oscillating action appeared more effective than sonic ones for plaque and gingivitis reduction. However, they noticed that the difference

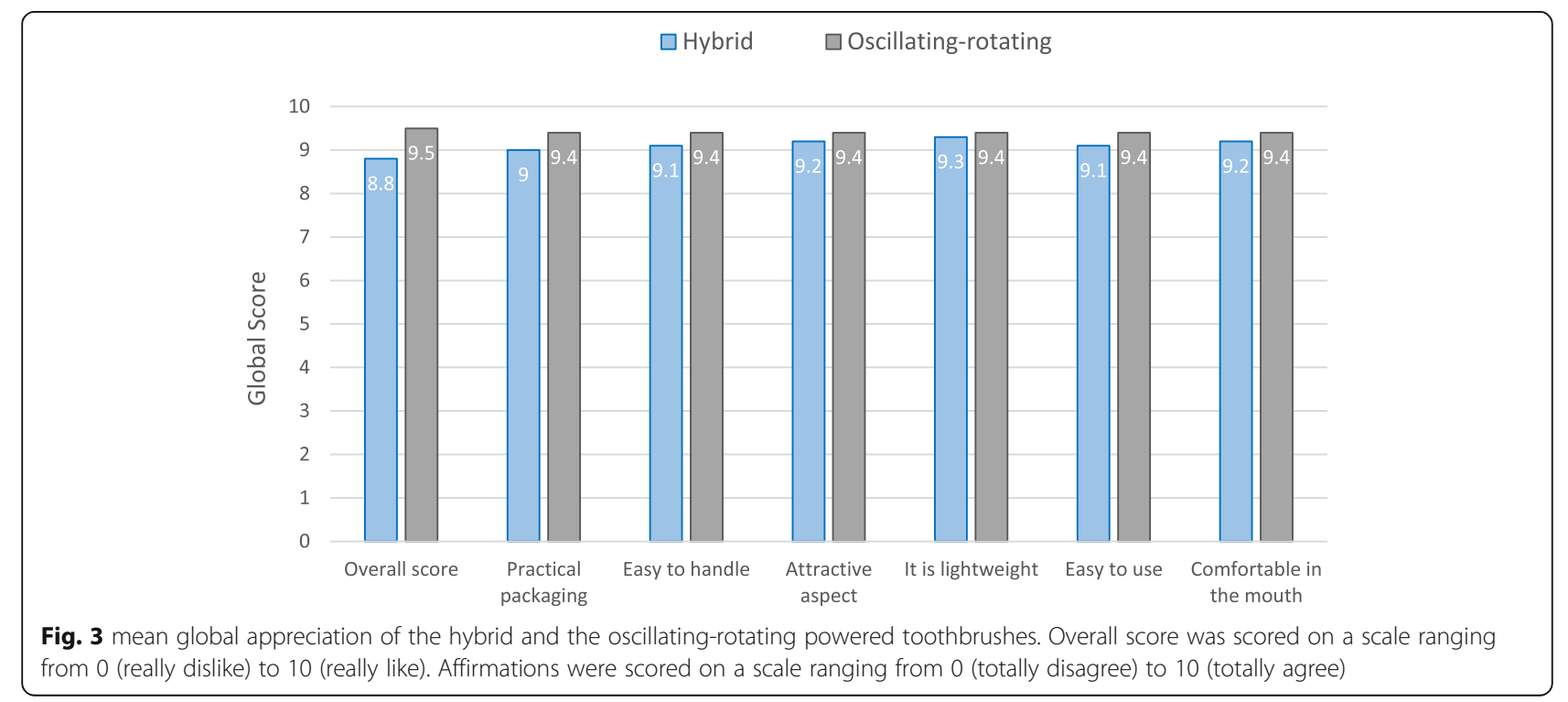




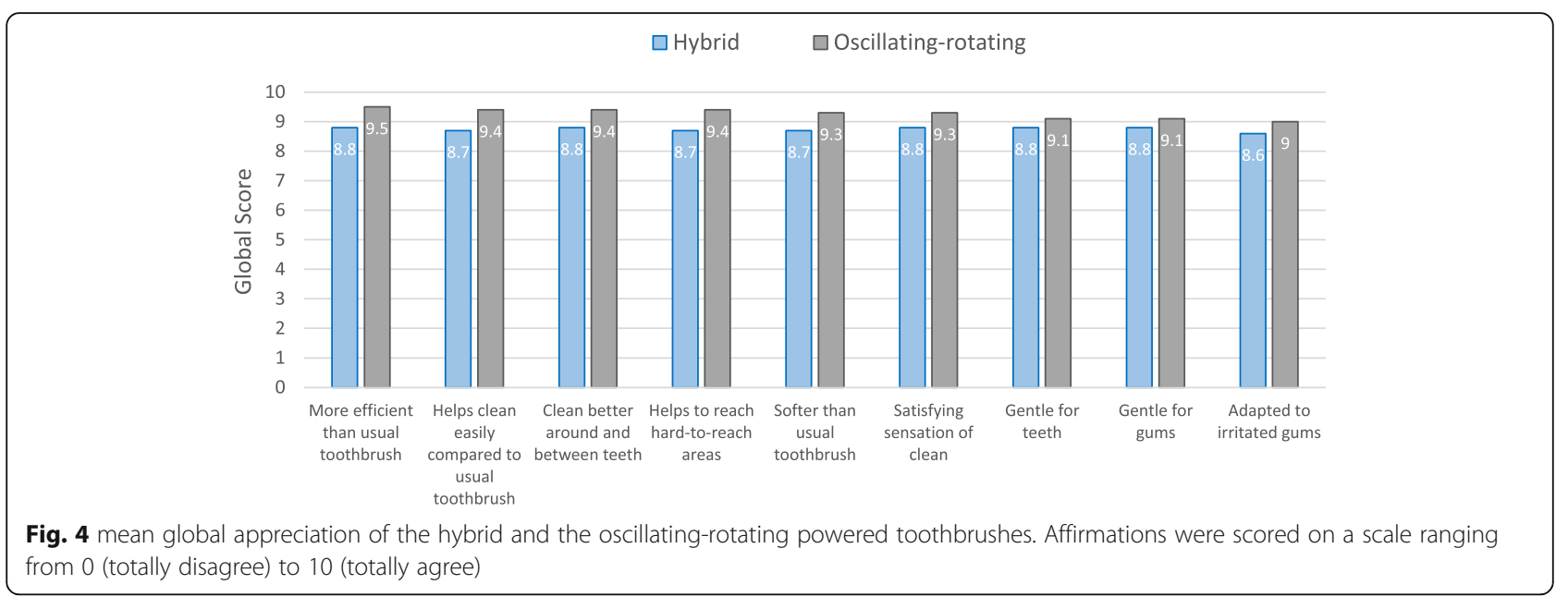

was small and its clinical importance, unclear. A recent review on the efficacy of powered toothbrushes following a single-use test highlighted the contribution of several factors to the observed efficacy on dental plaque: the power supply (rechargeable or replaceable battery), the mode of action, the brushing duration as well as the type of instructions [28]. The magnitude of the outcome was also highly dependent on the index scale used to score plaque for the evaluation.

These conflicting results may have contributed to the resistance of a portion of the population to becoming powered toothbrush users. Some consumers stay attached to their manual brushing experience, favor a traditional brush head characteristic and the ability to brush several teeth at once. Modifying oral hygiene habits is difficult to achieve and maintain over time [29]. Moreover, some of the powered toothbrush users sometimes return to their manual brush, either because of a vacation period, dead battery or hybrid usage (for example, manual tooth brushing in the morning and powered one in the evening) [30]. Based on these observations, the concept of a hybrid (manual and sonic) toothbrush emerged: the new brush evaluated in the present study was designed as a manual toothbrush with the addition of sonic technology. The final product is light (it weights three times less than the comparative marketed powered oscillating-rotating toothbrush), which can be an advantage for children or the elderly. It is space-saving since it does not need any electrical base. It is easy to carry and has a battery life of 1 month. The brush head needs to be replaced every 3 months, like any other toothbrush. "Hybrid" toothbrush means that it can be used either in manual mode, in sonic mode or in a combined mode (manual and sonic). Since the brush bristles are made of highly flexible Tinex ${ }^{\bullet}$ fibers, conically designed and rounded ended, a non-traumatic brushing of gums and enamel can be performed. Such bristles suit particularly well to sulcular tooth brushing. In this technique, the brush is positioned at about 45 degrees to the tooth and the tooth brush bristles are pushed into the sulcus [31]. The brush is then moved back and forth and removed by a downward and outward movement in the top arch. The toothbrush is moved to another tooth and the process is repeated. People presenting gum sensitivity can benefit from this gentle brush. In the manual mode, the user can keep his familiar brushing technique; in the sonic mode, the "non-contact" brushing linked to fluid dynamics completes the soft mechanical scrubbing. Sonic toothbrushes used in combination with a fluoride toothpaste demonstrate significantly less interproximal plaque and deliver significantly higher concentration of fluoride in that plaque, compared to manual or oscillatingrotating toothbrushes [32]. A standardized in vitro test -performed on a phantom tooth model cleaned by a robot proved that the hybrid toothbrush (combined mode) eliminates ten times more plaque in the approximal spaces compared to a conventional ADA manual toothbrush (internal data). Brushing exercise such as the one reported in the present study, proved that the plaque removal ability of the hybrid toothbrush used in the combined mode is as good as an oscillating-rotating one, considered as the gold standard mode. The percentages of plaque reduction obtained (around $45 \%$ ) are very similar to the one estimated by Rosema et al. for powered toothbrushes following a brushing exercise (46\% on average) [28]. The tolerance of the new toothbrush used in the combined mode was good as well as its overall appreciation. In order to investigate the improvement of gingival health, longer term studies should be performed in the future.

\section{Conclusion}

The results of this one-time use trial demonstrate that the hybrid toothbrush (used in the combined mode) is as good as a marketed oscillating-rotating toothbrush for plaque removal. The hybrid technology -offering the choice between 
either the traditional manual brushing technique, the sonic mode or the combined mode- allows each user to adapt tooth brushing to his desire, his skills or his mouth condition. We hypothesize that such an individualized approach can favor long term compliance with oral health recommendations and improve global oral wellness [33].

\section{Abbreviations}

ADA: American Dental Association; MGI: Modified Gingival Index; PI: Silness and Löe Plaque Index

\section{Acknowledgements}

Not applicable

\section{Funding}

Funding for this study was provided by Pierre Fabre Oral Care for the design of the study, collection, analysis, and interpretation of data as well as in writing the manuscript.

\section{Availability of data and materials}

The datasets generated during and/or analyzed during the current study are available from the corresponding author on reasonable request.

\section{Authors' contributions}

DK and MC drew up the study protocol in collaboration with JPG. DK and MC performed the clinical evaluations. AS wrote the article. DK, MC and JPG proofread the article. All the authors approved the final version of the article.

\section{Ethics approval and consent to participate}

In Poland, an electric toothbrush is considered to be a domestic electric apparatus. It is not considered as a drug nor a medical device, categories for which regulations do exist for conducting clinical trials. Therefore, in the absence of any regulations that applied to this specific category of products, conducting a clinical study with electric toothbrushes did not require any approval by an ethics committee. However, the study was conducted in compliance with Good Clinical Practices and in accordance with the "Declaration of Helsinki." Written informed consents for participation in the clinical study were obtained for all participants.

\section{Consent for publication}

Not applicable.

\section{Competing interests}

Dr. Gatignol is employee oflnnovation Unit Consumer HealthCare - Institut de Recherche Pierre Fabre

Dr. Klonowicz and Dr. Czerwinska received funding from Dermscan Poland for their collaboration to the study.

Dermscan Poland and Laboratoire Dermscan (A. Sirvent) are part of the Dermscan Group, a CRO that received funding from Pierre Fabre Oral Care to conduct the study.

Elgydium Clinic/Inava Hybrid toothbrush is marketed by Pierre Fabre Oral Care.

\section{Publisher's Note}

Springer Nature remains neutral with regard to jurisdictional claims in published maps and institutional affiliations.

\section{Author details}

'Dermscan Poland, UI. Kruczkowskiego 12, 80-288 Gdansk, Poland. 'Laboratoire Dermscan, 114 Bd du 11 novembre 1918, 69100 Villeurbanne, France. ${ }^{3}$ Innovation Unit Consumer HealthCare, 17 avenue Jean Moulin, 81106 Castres Cedex, France.

Received: 16 December 2016 Accepted: 22 October 2018 Published online: 06 November 2018

\section{References}

1. Van Der Weijden FA, Slot DE. Oral hygiene in the prevention of periodontal diseases: the evidence. Periodontol. 2011;55:104-23.
2. Baehni PC, Takeuchi Y. Anti-plaque agents in the prevention of biofilmassociated oral diseases. Oral Dis. 2003;9(suppl1):23-9.

3. Claydon N. Current concepts in toothbrushing and interdental cleaning. Periodontol 2000. 2008:48:10-22.

4. Choo A, Delac D, Brearley Messer L. Oral hygiene measures and promotion: review and considerations. Aust Dent J. 2001:46:166-73.

5. Löe H. Oral hygiene in the prevention of caries and periodontal disease. Int Dent J. 2000:50:129-39.

6. Grover D, Malhotra R, Kaushal S, Kaur G. Toothbrush - a key mechanical plaque control. Ind J Oral Sci. 2012;3:62-8.

7. American Dental Association. Available: http://www.mouthhealthy.org/en/ az-topics/b/brushing-your-teeth (accessed on October 10, 2016).

8. UFSBD. Available: http://www.ufsbd.fr/espace-grand-public/votre-santebucco-dentaire/recommandations-hygiene-bucco-dentaire (accessed on October 10, 2016).

9. Wainwright J, Sheiham A. An analysis of methods of toothbrushing recommended by dental associations, toothpastes and toothbrush companies and in dental texts. Br Dent J. 2014;217:E5.

10. Kinane DF. The role of interdental cleaning in effective plaque control: need for interdental cleaning in primary and secondary prevention. In: Lang NP, Attström R, Löe H, editors. Proceedings of the European workshop on mechanical plaque removal. Berlin: quintessence, publishing co.; 1998. p. 156-68.

11. Mastroberardino S, Grazia Cagetti M, Cocco F, Campus G, Pizzocri J, Strohmenger L. Vertical brushing versus horizontal brushing: a randomized split-mouth clinical trial. Quintessence Int. 2014;45:653-61.

12. Frandsen A. Mechanical oral hygiene practices. In: Löe H, Kleinman DV, editors. Dental plaque control measures and oral hygiene practices. OxfordWashington DC: IRL Press; 1986. p. 93-116.

13. MacGregor I, Rugg-Gunn A. A survey of toothbrushing sequence in children and young adults. J Periodontal Res. 1979;14:225-30.

14. Van der Weijden FA, Timmerman MF, Nijboer A, et al. A comparative study of electric tooth- brushes for the effectiveness of plaque removal in relation to toothbrushing duration. J Clin Periodontol. 1993;20:476-81.

15. Honkala E, Nyyssonen V, Knuuttila M, Markkanen H. Effectiveness of children's habitual toothbrushing. J Clin Periodontol. 1986;13:81-5.

16. Van der Weijden FA, Timmerman MF, Danser MM, et al. Approximal brush head used on a powered toothbrush. J Clin Periodontol. 2005:32:317-22.

17. Gallagher A, Sowinski J, Bowman J, et al. The effect of brushing time and dentifirice on dental plaque removal in vivo. J Dent Hyg. 2009:83:111-6.

18. Manhold J. 2015. About us: Inventor, Philippe-G. Woog, Ph.D. [Online]. BROXO. Available: http://eu.broxo.com/about-us/inventor (Accessed October 10, 2015).

19. Verma S, Bhat KM. Acceptability of powered toothbrushes for ederly individuals. J Public Health Dent. 2004;64:115-7.

20. Yaacob M, Worthington HV, Deacon SA, et al. Powered versus manual tooth brushing for oral health (review). Cochrane Database Syst Rev. 2014;6:art n CD002281.

21. Van der Weijden FA, Slot DE. Efficacy of homecare regimens for mechanical plaque removal in managing gingivitis: a meta review. J Clin Periodontol. 2015;42(Suppl16):S77-91.

22. Stanford CM, Srikantha R, Wu CD. Efficacy of the Sonicare toothbrush fluid dynamic action on removal of human supragingival plaque. J Clin Dent. 1997:8(1 Spec $\left.n^{\circ}\right): 10-4$

23. Hope CK, Wilson M. Effects of dynamic fluid activity from an electric toothbrush on in vitro oral biofilms. J Clin Periodontol. 2003;30:624-9.

24. Schmidt JC, Zaugg C, Weiger R, Walter C. Brushing without brushing? A review of the efficacy of powered toothbrushes in noncontact biofilm removal. Clin Oral Investig. 2013;17:687-709.

25. Löe $H$. The gingival index, the plaque index and the retention index systems. J Periodontol. 1967;38:610-6

26. Lobene RR, Weatherford T, Ross NM, et al. A modified gingival index for use in clinical trials. Clin Prev Dent. 1986:8:3-6.

27. Deacon SA, Glenny AM, Deery C, et al. Different powered toothbrushes for plaque control and gingival health. Cochrane Database Syst Rev. 2010;12:CD004971.

28. Rosema NAM, Slot D, Van Palenstein Helderman WH, et al. The efficacy of powered toothbrushes following a brushing exercise: a systematic review. Int J Dent Hyg. 2016;14:29-41.

29. Inglehart M, Tedesco LA. Behavioral research related to oral hygiene practices: a new century model of oral health promotion. Periodontol 2000. 1995:8:15-23 
30. Rosema NAM, Adam R, Grender JM, et al. Gingival abrasion and recession in the manual and oscillating-rotating power brush users. Int J Dent Hyg. 2014;12:257-66.

31. European Federation of Periodontology Available: http://weblink2.consultpro.com/user/BkojAog7yFCwPkwyV1ZnLQ (Accessed on November 4, 2016).

32. Sjörgren $K$, Lundberg $A B$, Birkhed $D$, et al. Interproximal plaque mass and fluoride retention after brushing and flossing - a comparative study of powered toothbrushing, manual toothbrushing and flossing. Oral Health Prev Dent. 2004;2:119-24.

33. Mariotti A, Hefti AF. Defining periodontal health. BMC Oral Health. 2015; 15(suppl1):S6.

Ready to submit your research? Choose BMC and benefit from:

- fast, convenient online submission

- thorough peer review by experienced researchers in your field

- rapid publication on acceptance

- support for research data, including large and complex data types

- gold Open Access which fosters wider collaboration and increased citations

- maximum visibility for your research: over $100 \mathrm{M}$ website views per year

At $\mathrm{BMC}$, research is always in progress.

Learn more biomedcentral.com/submissions 